\title{
Using the effluent treatment station sludge in the manufacture of red ceramics at the Iranduba / AM ceramic pole
}

\author{
Silvia Cibelle de Vasconcelos Moraes ${ }^{1}$, Giulliane Costa de Souza ${ }^{2}$
}

\author{
${ }^{1}$ Engenheira Ambiental pelo Centro Universitário do Norte (UNINORTE). Manaus - AM. \\ ${ }^{2}$ Discente em Engenharia de Produção pelo Centro Universitário do Norte (UNINORTE). Manaus - AM.
}

E-mail: silviacibelle@bol.com.br, giulliane_costa@hotmail.com

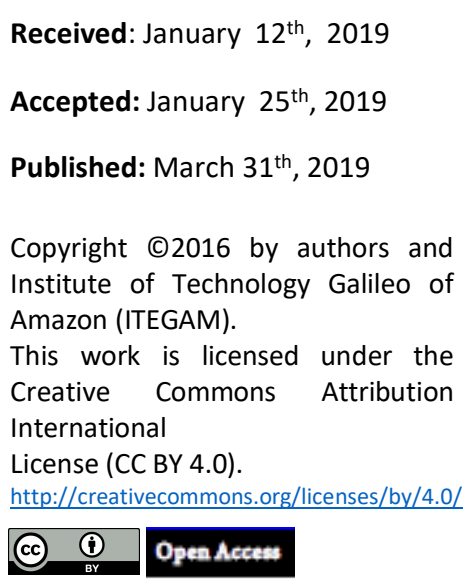

Received: January $12^{\text {th }}, 2019$

\section{ABSTRACT}

In the search for solutions capable of minimizing the environmental impacts from wastewater treatment plants of the industrial activities related to the final destination of waste generated (SLUDGE), the present work has the purpose of presenting the results of the incorporation of sludge from a treatment plant industrial and domestic effluents in the clay for the manufacture of red ceramics. The treatment plant sludge and the clay underwent chemical and mineralogical characterization through granulometric distribution, X-ray fluorescence analysis and X-ray diffraction. The samples were homogenized in the proportions of $0 \%, 5 \%, 7 \%$ and $10 \%$ by weight of the sludge in the clay, pressed at $25 \mathrm{MPa}$, and the characterization was carried out again by X-ray diffraction, proof and then burned at $900^{\circ} \mathrm{C}$. The physical and mechanical properties analyzed were: fire loss, linear retraction, water absorption, apparent specific mass, apparent porosity, Rupture to Bending stress and humidity. The results presented show similarity to the one recommended by ABNT and the base $(0 \%$ of sludge). Although the samples of $10 \%$ by weight of the sludge in relation to the clay show a variation in the chemical composition due to their high organic matter content, it was possible to observe that both had as main compound $\mathrm{SiO} 2, \mathrm{Al} 2 \mathrm{O} 3$ and $\mathrm{Fe} 2 \mathrm{O} 3$. The physical and mechanical analysis corresponded to with a maximum percentage of $10 \%$ by weight of the sludge, reaching the objectives of the work, making feasible the aggregation of the waste generated by the industrial and domestic effluent treatment plant.

Keywords: clay, industrial effluent sludge, red ceramics.

\section{Utilização do lodo de estação de tratamento de efluentes (ETE) na fabricação de cerâmica vermelha no polo ceramista de Iranduba/AM}

\section{RESUMO}

Em busca de soluções capazes de minimizar os impactos ambientais proveniente de estações de tratamento de efluentes (ETE) das atividades industriais relativas a destinação final dos resíduos gerados (LODO), o presente trabalho tem a finalidade de apresentar resultados da incorporação do lodo de uma estação de tratamento de efluentes (ETE) industrial e doméstico na argila para a fabricação de cerâmica vermelha. O lodo de ETE e a argila passaram por caracterizações químicas e mineralógicas, através de distribuição granulométrica, análise de fluorescência de raio-X e difração de raio-X. As amostras foram homogeinizadas nas proporções de 0\%, 5\%, $7 \%$ e $10 \%$ em peso do lodo na argila, prensadas a $25 \mathrm{Mpa}$, e realizado novamente a caracterização por difração de raio-X, posterior foi produzido os corpos-de-prova e em seguida queimados a $900^{\circ} \mathrm{C}$. As propriedades físicas e mecânicas analisadas foram: perda ao fogo, retração linear, absorção de água, massa específica aparente, porosidade aparente, tensão de Ruptura à Flexão e umidade. Os resultados apresentados mostram semelhança ao recomendado pela ABNT e pela base (0\% de lodo). Apesar das amostras de $10 \%$ em peso do lodo em relação a argila demonstrarem variação na composição química devido sua elevada taxa de matéria orgânica, pôde se observar que ambas tiveram como composto majoritário o $\mathrm{SiO} 2$, Al2O3 e Fe2O3.As análises físicas e mecânicas corresponderam de forma positiva, apresentando resultados muito promissores para a fabricação da cerâmica vermelha com a porcentagem máxima analisada de $10 \%$ em peso do lodo, alcançando os objetivos do trabalho tornando viável a agregação do resíduo gerado pela estação de tratamento de efluente industrial e doméstica.

Keywords: Argila, lodo de efluente industrial, cerâmica vermelha. 


\section{INTRODUÇÃO}

Em meados do século XX com advento da era Vargas o Brasil expandiu a industrialização, e com o marco histórico surgiu o crescimento econômico e populacional, que de fato desencadeou o consumo desenfreado dos recursos naturais e consequentemente a degradação do ecossistema e a poluição do meio ambiente [1]. Por tanto são inumeráveis as causas das alterações ambientais oriundas das ações antrópicas e naturais, modificando paisagens e comprometendo o ecossistema, em especial ao ambiente urbano [2]. Dentre as inumeráveis causas, a prática inadequada da disposição de resíduos gerados pela indústria tem sido uma das principais preocupações [3].

É crescente a preocupação com a sustentabilidade nas organizações, tornando um dos maiores desafios para sobrevivência da humanidade, surgindo à necessidade de estabelecer alguns padrões normativos para regulamentar os aspectos de controle ambiental facilitando na avaliação, [4]. O processo de tratamento adequado de uma ETE, geralmente é por meio físico-químico por batelada onde são estocados, formando misturas de resíduos similares até serem encaminhados para os reatores, e posteriormente recebem o tratamento adequado (precipitação química, quebra ácida, oxidação, redução, entre outros), e assim o efluente retorna para a natureza e o lodo é armazenado aguardando sua destinação final [5]. Qualquer estação de tratamento em que não se consiga alguma forma de disposição final do lodo está fatalmente condenada ao insucesso, assim, o tratamento e disposição de lodo devem ser geridos para minimizar problemas ambientais como odor e lançamento no ambiente de contaminantes e patógenos de acordo com [6].

O lodo de ETE é considerado um dos mais prejudiciais a vida dos seres humanos, pois causa a poluição dos rios e afeta a saúde da população. Porém é muito rico em matéria orgânica e em macro e micronutrientes [7]. A principal matéria-prima utilizada na indústria de cerâmica é a argila, dependendo de sua natureza tem sua granulometria fina e abrange uma grande variedade de substanciais minerais [8]. Visando alcançar o objetivo macro deste trabalho efetuou-se a caracterização as matérias primas, a argila e o lodo (ETE) por meio de analises químicas e difração de raio-X, preparar os corpos-de-prova com teores de $0,5,7$ e $10 \%$ de peso do lodo agregado a massa cerâmica (argila) e realizar ensaios físicos e mecânicos dos corpos-de-prova com diferentes teores [9].

Desta forma, o objetivo geral deste trabalho é analisar a viabilidade da agregação do lodo gerado na Estação de Tratamento de Efluentes (ETE) de uma indústria de produção do ramo de higiene e limpeza, na matéria prima da fabricação de cerâmica vermelha do Polo Ceramista de Iranduba-AM e assim minimizar os impactos ambientas gerados na disposição final deste resíduo (lodo) [10].

Portanto, é muito importante para a região do Amazonas saber que existem diversas formas de minimizar os impactos negativos ao meio ambiente, gerados pela disposição final de resíduos sólidos (lodo) através das estações de tratamento de

efluentes (ETE) proveniente do pólo industrial, bem como lançar possibilidade de alternativa ecológica de aproveitamento do resíduo (lodo) como matéria prima na indústria de cerâmica vermelha do município de Iranduba.

Dessa forma, tem-se como objetivo analisar a viabilidade da agregação do Lodo de Estação de Tratamento de efluentes
(ETE) na fabricação de cerâmica vermelha, buscando minimizar os impactos ambientais gerados na disposição final deste resíduo, caracterizando as matérias-primas, a argila e o lodo (ETE) por meios físico (difração granulométrica), quimíco (fluorescência de raio-X) e minerológica (difração de raio-X); preparando corposde-prova nos teores de $0 \%, 5 \%, 7 \%$ e $10 \%$ de lodo agregado a massa cerâmica; e realizando ensaios físicos e mecânicos nos corpos-de-prova em diferentes teores de resíduo.

\section{MATERIAL E MÉTODOS}

Para o presente estudo, foram coletadas duas matériasprimas, provenientes de distintas áreas de estudos.

A primeira matéria-prima foi à argila, coletada de um terreno de propriedade da empresa Cerâmica Montemar Ltda, situada no Km 30 da rodovia Manuel Urbano, no município de Iranduba no Estado do Amazonas, onde são utilizadas industrialmente para a fabricação de cerâmicas vermelhas (FIGURA 1). Os métodos de coletas foram através de sistema mecânico com utilização de retroescavadeira e caçamba. Para o estudo, a argila foi coletada em porta-amostra e acondicionada em tonéis de papelão vedado com braçadeira de aço e armazenada para ser encaminhada aos laboratórios.

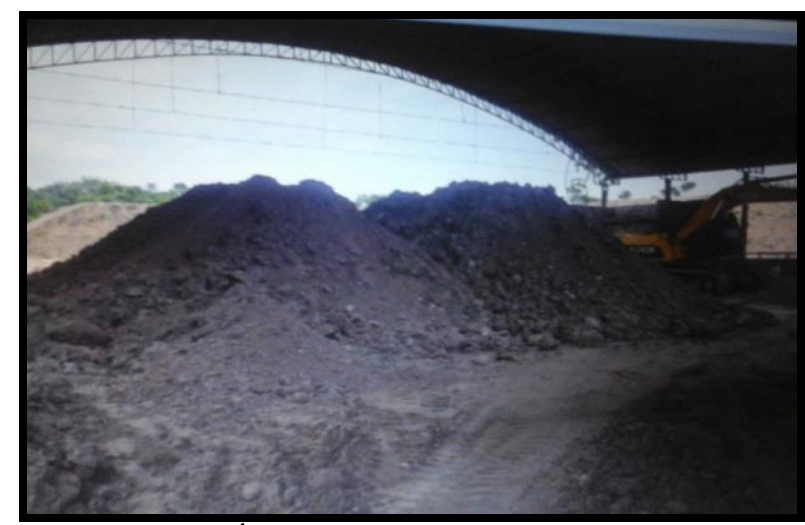

Figura 1: Área de coleta da argila para estudo. Fonte: Autores, (2018)

A segunda matéria-prima foi o lodo, cedido pela gerência de uma empresa industrial do ramo de higiene e limpeza situada na estrada BR174, no Km 02, bairro Tarumã da cidade de Manaus/Am, a amostra foi coletada da caçamba de armazenamento temporário da estação de tratamento de efluente (ETE), depois de ter passado por todo o processo de tratamento (Figura 2).

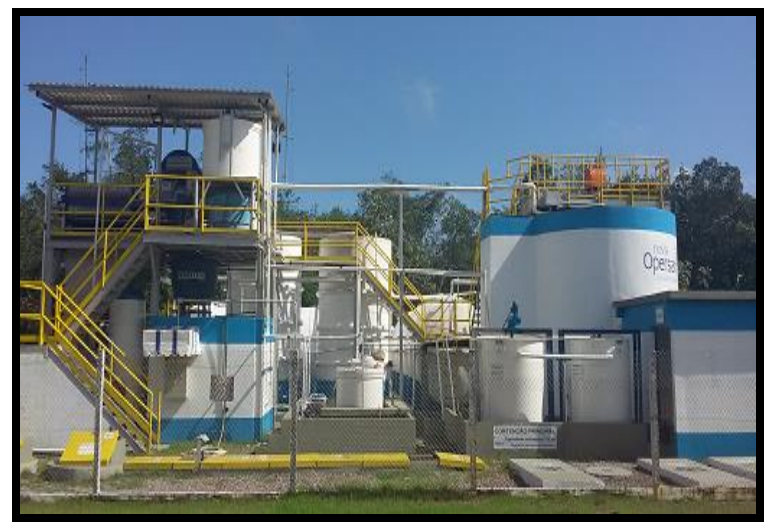

Figura 2: Estação de tratamento de Efluente de onde foi coletado o lodo. Fonte: Opersan, (2018). 
Tanto a argila quanto o lodo de ETE foram encaminhados aos laboratórios de Geotecnia (mecânica dos solos) da Universidade Uninorte, ao laboratório de Geoquímica do Departamento de Geociências da Universidade Federal do Amazonas (UFAM), ao laboratório de química do Grupo Crowfoot da Escola Superior de Tecnologia da Universidade do Estado do Amazonas (UEA) e ao laboratório Temático Institucional de Química de Produtos Naturais (LTQPN) do Instituto de Pesquisa Nacional da Amazônia (INPA), para a realização de diferentes ensaios da matéria-prima, determinado suas caracterizações, propriedades físicas e mecânicas conforme as etapas (Figura 3).

\begin{tabular}{|c|c|}
\hline & $\begin{array}{l}\text { - Lodo de ETE } \\
\text {-Argila }\end{array}$ \\
\hline & -Preparação individual das amostras \\
\hline & -Granulometria \\
\hline & $\begin{array}{l}\text {-Análise química } \\
\text {-Difração de Raio - X (DRX) }\end{array}$ \\
\hline & $\begin{array}{l}\text {-Homogeneização das amostras } \\
\text {-Prensagem } \Rightarrow \text { secagem } \Rightarrow \text { queima }\end{array}$ \\
\hline & $\begin{array}{l}\text { - Retração linear }{ }^{2} \text { absorção de água } \Rightarrow \text { porosidade aparente } \\
\text { - Massa espec. aparente }{ }_{\text {Tensao de ruptura }} \Rightarrow \text { Difração de Raio - } x\end{array}$ \\
\hline
\end{tabular}

Figura 3: Fluxograma simplificado dos procedimentos. Fonte: Autores, (2018).

Inicialmente as amostras foram submetidas a um processo de secagem e destorroamento. A secagem foi realizada em estufa elétrica com 0 termostato regulado em $110{ }^{\circ} \mathrm{C} \pm 5{ }^{\circ} \mathrm{C}$ por um período de $24 \mathrm{~h}$. Após essa secagem, as amostras foram destorroadas com o auxílio de almofariz em quantidade suficiente para realizar todos os ensaios e acondicionadas em recipientes plásticos.

\section{II.1 CARACTERIZAÇÃO DA MATÉRIA-PRIMA}

A caracterização da matéria-prima foi realizada através de Difração granulométricas, Fluorescência de Raio-X (FRX), Difração de Raio-X (DRX) conforme NBR 7181/84.

\section{II.1.1 ANÁLISE GRANULOMÉTRICA}

Foi usado o método de sedimentação dos sólidos no meio líquido, onde os materiais (lodo e argila) foram pesados em balanças elétricas, separando $2000 \mathrm{~g}$ de cada amostra e passada separadamente na peneira de $\mathrm{n}^{\mathrm{o}} 10(2,00 \mathrm{~mm})$, o material retido na peneira foi acondicionado em uma bacia de alumínio e identificado como material grosso, do material que passou na peneira de $\mathrm{n}^{\mathrm{o}} 10(2,00 \mathrm{~mm})$ foi retirado $200 \mathrm{~g}$ e identificado como material fino, acondicionado em uma nova bacia (NBR 7181, 1984).

\section{II.1.1.1 TEOR DE UMIDADE}

Neste processo pesou-se 3 capsulas numeradas vazias para cada material, ou seja, 6 capsulas e anotando os pesos de cada uma delas, onde chamaremos de P1a e P11. Em seguida foi colocado aproximadamente $50 \mathrm{~g}$ do material na capsula e pesado novamente, onde foi chamado de P2a e P21. O material foi para a estufa elétrica com a temperatura de $110^{\circ} \mathrm{C}$ por 24 horas. Ao tirar as capsulas da estufa, pesou-se novamente e o resultado foi chamado de P3a e P31.

As fórmulas utilizadas para obter os resultados foram:

a)

b)

c)

d)
Peso da água $(\mathrm{g})$

$\mathrm{Pa}=\mathrm{P} 2-\mathrm{P} 3$

Peso do solo seco (g)

$\mathrm{Ps}=\mathrm{P} 3-\mathrm{P} 1$

Teor de umidade $(\%)$

$\mathrm{H} \%=\mathrm{Pa} / \mathrm{Ps} \times 100$

Fator de correção

$\mathrm{Fc}=100 / 100+\mathrm{h} \%$

O resultado de umidade higroscópica e o fator de correção (Tabela 1) serviram como base de cálculo para a análise granulométrica.

Tabela 1: Teor de umidade das amostras.

\begin{tabular}{l|c|c}
\hline \multicolumn{1}{c|}{ Resultado encontrado (média) } & Lodo ETE- P3I & Argila - P3a \\
\hline Peso cápsula (g) & 21,36 & 14,07 \\
\hline Cápsula e solo umido $(\mathrm{g})$ & 73,96 & 87,31 \\
\hline Cápsula e solo seco $(\mathrm{g})$ & 66,84 & 85,89 \\
\hline Solo seco $(\mathrm{g})$ & 45,48 & 71,82 \\
\hline Agua (g) & 7,12 & 1,42 \\
\hline Umidade higroscópica(\%) & 3,58 & 3,59 \\
\hline Fator de correção & 0,97 & 0,97 \\
\hline
\end{tabular}

Fonte: Autores, (2018)

Nesta etapa as amostras (argila e lodo ETE) foram submetidas ao processo de peneiramento e depois pelo método de sedimentação dos sólidos no meio líquido (Figura 4).

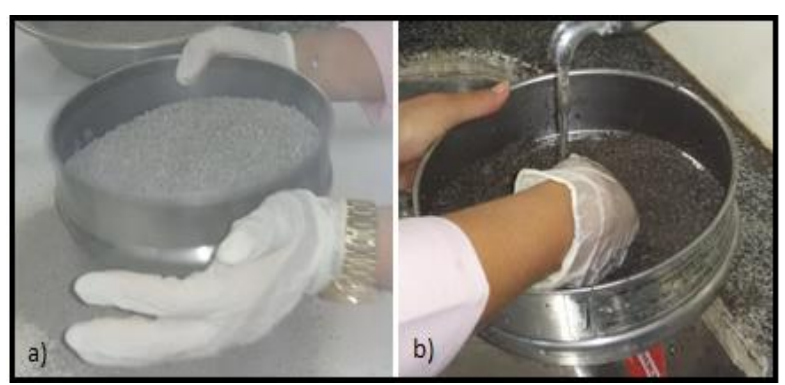

Figura 4: (a) - Peneiramento da amostra. (b) - Sedimentação da amostra. Fonte: Autores, (2018).

O material grosso (argila e Lodo) que ficou retido na peneira de $\mathrm{n}^{\circ} 10$ foi lavado com água corrente até que a água fique limpa (transparente) devolvendo o material da peneira para o recipiente de alumínio e levando - o para a estufa a temperatura de $110^{\circ} \mathrm{C}$ novamente onde permaneceu por 12 horas, após as 12 horas o material seco foi retirado da estufa e realizado o processo de peneiramento passando pelas seguintes peneiras: $1^{1 / 2}$, 1 ", 3/4",3/8", No4, No10 (Figura 5).

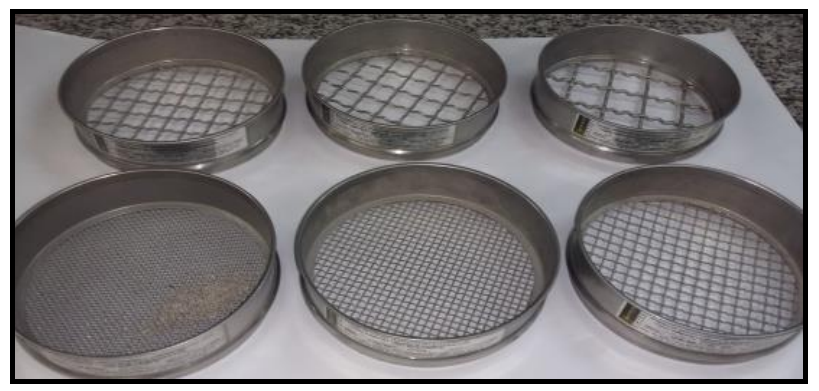

Figura 5: Peneiras do material grosso para a separação de grãos. Fonte: Autores, (2018). 
O material fino (argila e Lodo) que ficou retido na peneira de $n^{\circ} 200$ foi lavado com água corrente até que a água ficasse limpa (transparente) devolvendo o material da peneira para o recipiente de alumínio e levando - o para a estufa a temperatura de $110^{\circ} \mathrm{C}$ novamente onde permanecerá por 12 horas, após as 12 horas o material seco foi retirado da estufa e realizado o processo de peneiramento passando pelas seguintes peneiras: $\mathrm{N}^{\circ} 16, \mathrm{~N}^{\circ} 30, \mathrm{~N}^{\circ} 40, \mathrm{~N}^{\circ} 50, \mathrm{~N}^{\circ} 100, \mathrm{~N}^{\circ} 200$ (Figura 6).

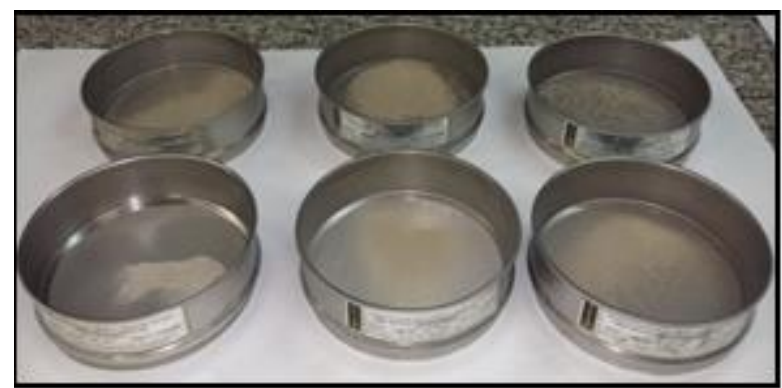

Figura 6: Peneiras do material fino para a separação de grãos. Fonte: Autores, (2018).

Depois de peneirar mensurou-se o peso de cada amostra retida na peneira e realiza os seguintes cálculos:

Material grosso: calculou-se o peso do material retido na peneira $\mathrm{n}^{\circ} 10$, somando o peso das amostras retidas em todas as peneiras. Obter porcentagem da Amostra Total.

\section{$\operatorname{Pr} /$ Ps x 100}

Obtenção de porcentagem acumulado, é a soma do resultado encontrado na porcentagem da amostra total. Obtenção de porcentagem que passa da amostra total, é subtraído $100 \%$ pelo valor encontrado na porcentagem acumulada.

Material fino: Calculou-se a amostra parcial seca, multiplicando-se pela amostra parcial úmida pelo fator de correção da umidade higroscópica. Obtenção de porcentagem da amostra total, é dividido o peso retido pelo o peso da amostra parcial seca, multiplicado por 100 .

\section{$\operatorname{Pr} /$ Ps x 100}

Obtenção de porcentagem de acumulado, é a soma do resultado encontrado na porcentagem da amostra total. Para de obter porcentagem da que passa da amostra parcial, é subtraído $100 \%$ pelo valor encontrado na porcentagem acumulado.Para se obter porcentagem que passa da amostra total, é coletado o último valor da porcentagem que passa da amostra total da peneira $\mathrm{n}^{\circ} 10$, multiplicado pelo valor da \% que passa na amostra parcial, dividido por 100 .

\section{II.1.2 FLUORESCÊNCIA DE RAIO-X}

Foram realizadas as análises químicas da argila e lodo moído (10g de cada) através da Fluorescência de Raio-X. Esta é uma técnica analítica multielementar e não destrutiva usada para obter informações qualitativas e quantitativas da composição elementar das amostras.

Para análises das amostras, o lodo e argila foram conformados em pastilhas de ácido bórico (Figura 7), prensados em prensa pneumática de marca Rigaku, modelo PCA 30.

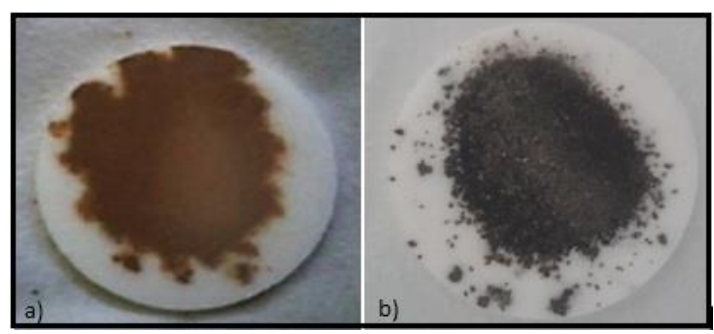

Figura 7: (a) - Pastilha de Argila

(b)- Pastilha do lodo de ETE. Fonte: Autores, (2018).

Após conformação as amostras foram colocadas no Espectrômetro (Figura 8) para fluorescência de Raio-X, da marca RIGAKU, Modelo Supemini, afim de se quantificar os elementos químicos presentes nas amostras.

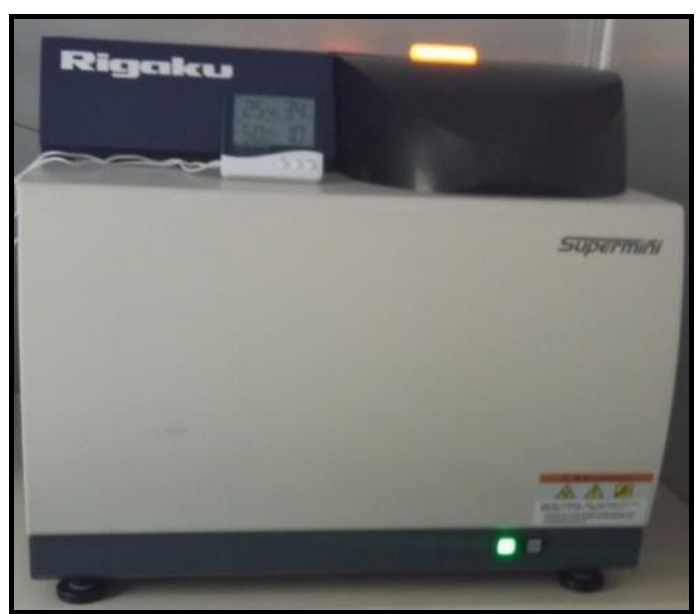

Figura 8: Espectrômetro para Fluorescência de Raio-X. Fonte: Autores, (2018).

\section{II.1.3 DIFRAÇÃO DE RAIO-X}

Para as análises da estrutura foi utilizado $20 \mathrm{~g}$ dos materiais (lodo e argila) passante na peneira de $n^{\circ} 200$ (abertura de $74 \mathrm{~mm}$ ), adicionando água destilada e hidróxido de amônio $(\mathrm{NH} 4 \mathrm{OH})$, agitou-se e foram para a secagem em estufa a $100^{\circ} \mathrm{C} \mathrm{e}$ porterior colocado em lámina para identificação da composição mineralógica da argila e lodo de ETE, foi utilizado um aparelho de difração de raio-X, da marca LAB-X SHIMADZU, modelo XRD - 6000 com tubo de raio-X cerâmico e anodo de cobre (Figura 9).

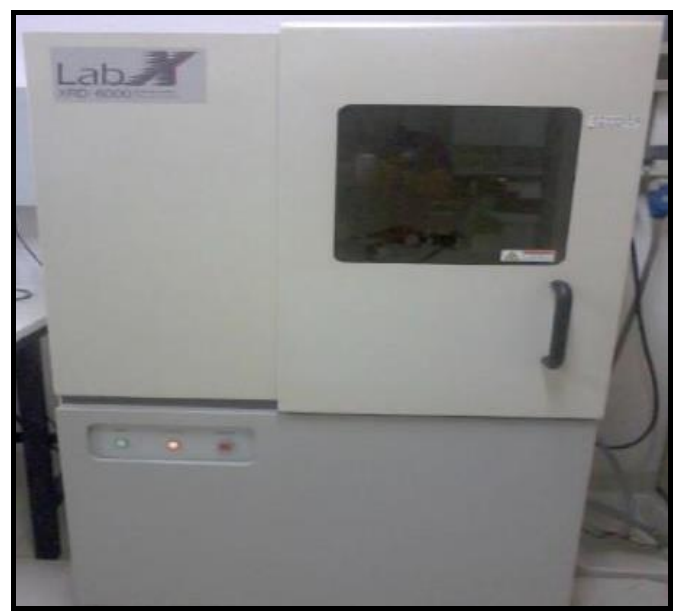

Figura 9: Equipamento de Difração de raio-X. Fonte: Autores, (2018). 
As condições instrumentais utilizadas foram: $5^{\circ}$ a $7^{\circ} \mathrm{em}$ 2Ө; voltagem de $40 \mathrm{kV}$ e corrente de $30 \mathrm{~mA}$; tamanho do passo: $0,017^{\circ}$ em $2 \Theta$ e 10,34 s o tempo/passo; fenda divergente $1 / 4^{\circ}$ e anti-espalhamento de $1 / 2^{\circ}$; máscara de $10 \mathrm{~mm}$; amostra em movimentação circular com frequência de 1 rotação/s. O software usado para o processamento de dados foi o OrigimPro 8.

\section{II.2. PREPARAÇÃO DOS CORPOS DE PROVA}

Após caracterização as matérias-primas foram submetidas ao processo homogeneização para formulação da massa cerâmica em diferentes proporções. Em seguida foram realizadas prensagem, secagem e queima dos corpos de prova.

Foram confeccionados corpos de prova com diferentes proporções de resíduo na argila, sendo $0 \%, 5 \%, 7 \%$ e $10 \%$.

\section{II.2.1 FORMULAÇÃO E HOMOGENEIZAÇÃO}

Para a formulação e homogeneização da massa cerâmica, foi utilizada uma balança analítica de marca Marte, modelo AS 1000 C Classe II, calibrada de acordo com a portaria do INMETRO/Dimel no 002/2004 (Figura 10).

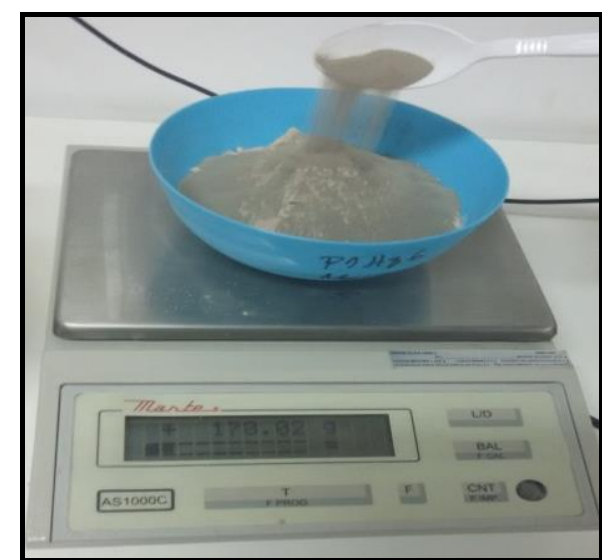

Figura 10: Balança analítica usada para formulação da massa cerâmica. Fonte: Autores, (2018).

Nessa etapa, pesou-se a matéria-prima variando a concentração de resíduo em $0 \%, 5 \%, 7 \%$, e $10 \%$, com uma umidade de $10 \%$ para obter uma melhor uniformidade na conformação dos corpos de prova. Essa umidade foi obtida através da adição de água na matéria-prima seca durante o processo de formulação da massa cerâmica (Tabela 2).

Tabela 2: Formulação e homogeneização da massa cerâmica.

\begin{tabular}{|c|c|c|c|c|c|}
\hline Corpos- & & \multicolumn{4}{|c|}{ \% em peso de matéria prima } \\
\cline { 3 - 6 } $\begin{array}{c}\text { de- } \\
\text { prova }\end{array}$ & $\begin{array}{c}\text { Massa } \\
\text { cerâmica }\end{array}$ & Argila & Lodo & Umidade & Total \\
\hline 1 & $0 \%$ & 90 & 0 & 10 & 100 \\
\hline 2 & $5 \%$ & 85 & 5 & 10 & 100 \\
\hline 3 & $7 \%$ & 83 & 7 & 10 & 100 \\
\hline 4 & $10 \%$ & 80 & 10 & 10 & 100 \\
\hline
\end{tabular}

Cada mistura foi submetida a um processo de homogeneização por cerca de 30 minutos manualmente e separando para cada corpo-de prova a quantidade de $30 \mathrm{~g}$ da massa cerâmica. Foram pesadas através de uma balança analítica com capacidade máxima de $310 \mathrm{~g}$ e mínima de $0,001 \mathrm{~g}$, da marca Adventurer OHUS, modelo AR 3130 Classe II, com cabine, calibrada de acordo com a portaria do INMETRO/Dimel $\mathrm{n}^{\circ}$ 002/2004 (Figura 11).

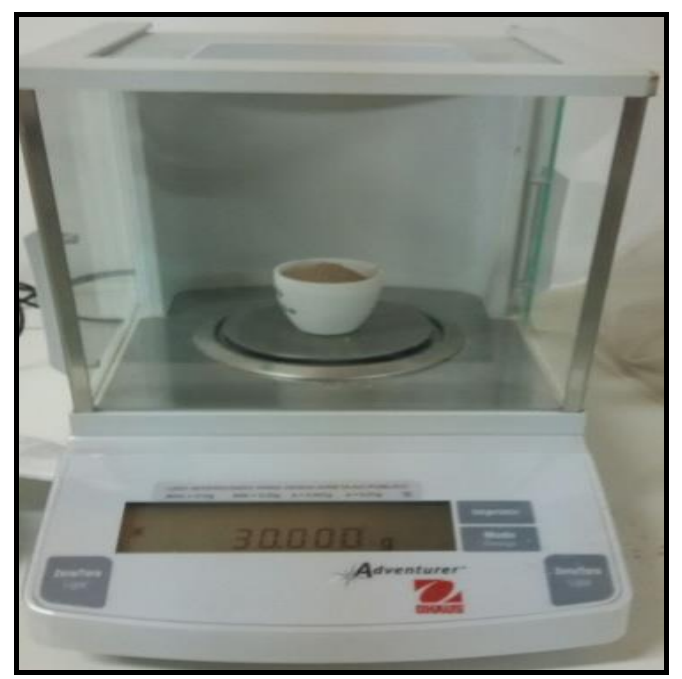

Figura 11: Balança de precisão com cabine. Fonte: Autores, (2018).

\section{II.2.2 PRENSAGEM}

A prensagem é uma das etapas básicas do processamento dos materiais a partir do pó, na qual obteve a forma estrutural da peça, como também as primeiras propriedades do produto. Nessa etapa foi utilizado um molde de aço sob o formato retangular, com dimensões de 70,54 x 30,37 x 8,20 mm, onde foi conformado as peças para realização dos ensaios. Para o processo de prensagem os corpos de prova foram colocados no molde e levados a uma prensa hidráulica marca MARCONI, com capacidade máxima de até 20 toneladas, onde foi utilizado sob pressão de $25 \mathrm{Mpa}$ por um minuto. Foram confeccionados 24 (vinte e quatro) corpos de prova, sendo 6 (seis) para cada ensaio, onde 5 (cinco) são para as análises e 1 (um), mantido como corpo de segurança. Após a prensagem foi realizado o dimensionamento dos corpos de prova verde, determinados através de medições do paquímetro digital 0-200mm profissional de aço inoxidável, da marca ZAAS Precision, modelo Stainless Hafoi, onde por meio deste foi medido comprimento, largura e espessura respectivamente. O peso médio de $29,87 \mathrm{~g}$, obtidos através de balança analítica com capacidade máxima de $310 \mathrm{~g}$ e mínima de 0,001g, da marca Adventurer OHUS, modelo AR 3130 Classe II, calibrada de acordo com a portaria [11], onde foi desprezado a força da gravidade para que fosse determinado a densidade verde do material prensado.

As medições e pesagem são fundamentais para obtenção de massa e volume, variáveis que serão utilizadas para determinar a densidade.

A densidade foi determinada através da formula:

$$
D=\frac{m}{v} \quad\left(\mathrm{~g} / \mathrm{mm}^{3}\right)
$$

Onde:

$$
\begin{aligned}
& \mathrm{D}=\text { Densidade } \\
& \mathrm{m}=\text { Massa } \\
& \mathrm{V}=\text { Volume }
\end{aligned}
$$

Deste cálculo foram obtidos resultados para cada uma das formulações em diferentes proporções de argila, resíduo e umidade respectivamente. Este resultado tem como objetivo 
prever hipoteticamente as possíveis alterações que foram obtidos nos ensaios físicos e mecânicos.

\section{II.2.3 SECAGEM DOS CORPOS-DE-PROVA}

A secagem tem por objetivo remover a água na superfície dos corpos de prova por evaporação e por difusão na parte interna, antes de submetê-los ao processo de sinterização. Nessa etapa, devido a remoção da água, pode ocorrer pequenas contrações de volume, desejáveis para permitir uma aproximação das partículas constituintes, evitando com, isso a ocorrência de defeitos nas amostras durante a queima. Dessa forma tomou-se cuidado em controlar a temperatura de secagem, pois um efeito negativo dessas contrações pode ocorrer quando a taxa de evaporação for maior que a taxa de difusão, a superfície irá secar contraindo seu volume mais rapidamente que o interior, ocasionando deformações nas amostras.

Para esse caso os corpos de prova moldados foram colocados em estufa da marca modelo MA033 da marca MARCONI, serie FO7170, (FIGURA 12) com temperatura a $110^{\circ} \mathrm{C}$ por $24 \mathrm{~h}$.

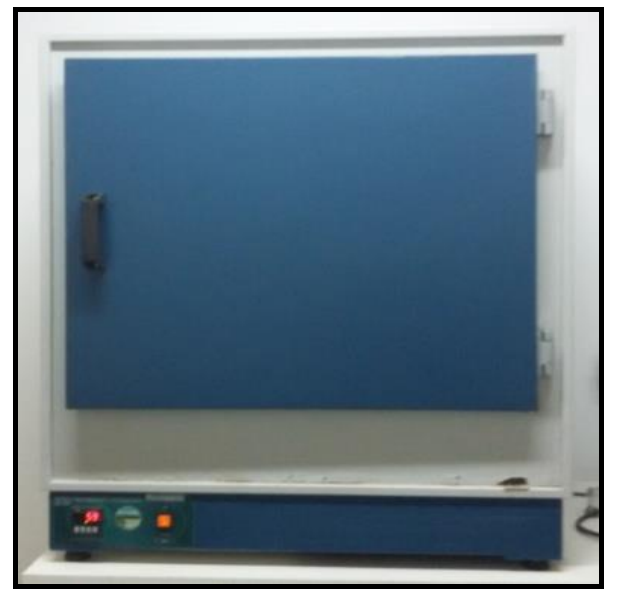

Figura 12: Estufa de secagem dos corpos-de-prova. Fonte: Autores, (2018).

Após a secagem foi realizado o dimensionamento dos corpos de prova seco, determinados através de medições do paquímetro digital 0-200mm profissional de aço inoxidável, da marca ZAAS Precision, modelo Stainless Hafoi, onde foi medido comprimento, largura e espessura respectivamente. Este procedimento visa verificar o comportamento dos minerais expostos a temperatura, qual a possibilidade de expansão ou retração (Tabela 3 ).

Tabela 3: Medidas dos corpos de prova após secagem em estufa à $110^{\circ} \mathrm{C}$.

\begin{tabular}{|c|c|c|c|c|c|}
\hline \multirow{2}{*}{$\begin{array}{c}\text { Corpos } \begin{array}{c}\text { Massa } \\
\text { de } \\
\text { prova }\end{array} \\
\text { cerâmica }\end{array}$} & \multicolumn{4}{|c|}{ Dimensões após secagem (mm) } \\
\cline { 3 - 6 } & & Comprimento & Largura & Espessura & Peso \\
\hline 1 & $0 \%$ & 72,07 & 31,69 & 7,67 & 26,86 \\
\hline 2 & $5 \%$ & 71,85 & 31,48 & 7,9 & 26,83 \\
\hline 3 & $7 \%$ & 71,9 & 31,54 & 7,88 & 26,74 \\
\hline 4 & $10 \%$ & 71,92 & 31,69 & 7,96 & 26,67 \\
\hline \multicolumn{2}{|c|}{ Média } & $\mathbf{7 1 , 9 3 5}$ & $\mathbf{3 1 , 6}$ & $\mathbf{7 , 8 5 2 5}$ & $\mathbf{2 6 , 7 7 5}$ \\
\hline
\end{tabular}

\section{II.2.4 QUEIMA DOS CORPOS-DE-PROVA}

O processo de queima dos corpos de prova foi realizado em fornos elétrico Mufla microprocessado marca QUIMIS, modelo Q318M24, série 13020922 (figura 13), onde utilizou-se temperaturas de sinterização a $900^{\circ} \mathrm{C}$ com 3 (três) patamares diferentes, sendo o $1^{\circ}$ (primeiro) de 3 minutos a $450^{\circ} \mathrm{C}$, o $2^{\circ}$ (segundo) de 3 minutos a $650^{\circ} \mathrm{C}$ e o patamar final de 30 minutos a $900^{\circ} \mathrm{C}$, os intervalos entre os patamares foi de 60 minutos, 30 minutos e 60 minutos respectivamente somando um tempo de 186 minutos.

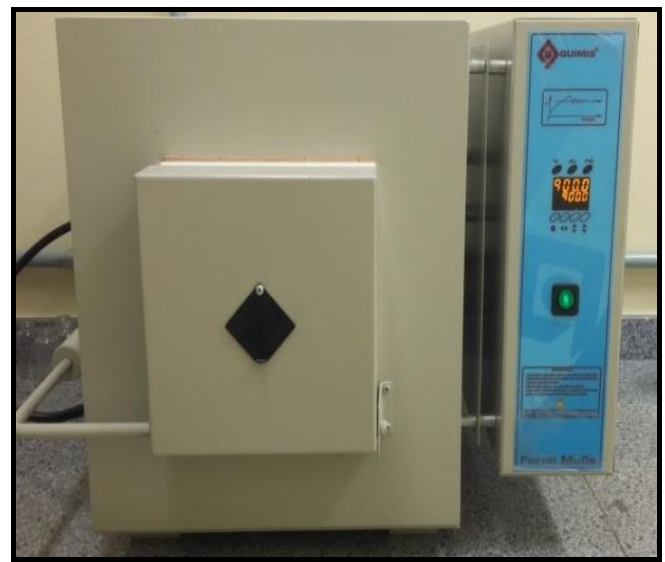

Figura 13: Forno Mufla utilizado para queirma dos corpos de prova.

Fonte: Autores, (2018).

A temperatura inicial foi de $20^{\circ} \mathrm{C}$ com taxa de aquecimento de $5^{\circ} \mathrm{C} / \mathrm{min}$ com isotermia de 30 minutos e taxa de resfriamento de $75^{\circ} \mathrm{C}$ por hora em um intervalo de 12 horas, como podemos observar na (Figura 14).

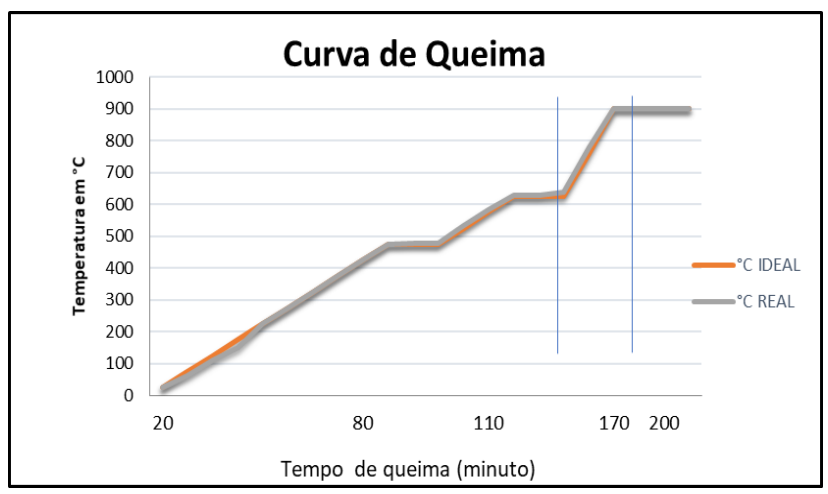

Figura 14. Curva de queima dos corpos de prova. Fonte: Autores, (2018).

Na Tabela 4, observa-se a temperatura de queima e os patamares dos corpos de prova.

Tabela 4: Temperatura de queima dos corpos de prova.

\begin{tabular}{|c|c|c|c|c|c|c|}
\hline \multicolumn{2}{|c|}{$\begin{array}{c}\% \text { Peso da } \\
\text { matéria prima }\end{array}$} & \multirow{2}{*}{$\begin{array}{c}\text { Corpos de } \\
\text { prova }\end{array}$} & \multicolumn{4}{|c|}{ Temperatura de Queima $\left({ }^{\circ} \mathrm{C}\right)$} \\
\hline Argila & Lodo & & $\begin{array}{l}\text { Tempo } \\
\text { inicial }\end{array}$ & $\begin{array}{c}\text { Patamar } \\
3 \text { min }\end{array}$ & $\begin{array}{c}\text { Patamar } \\
3 \mathrm{~min}\end{array}$ & $\begin{array}{c}\text { Tempo } \\
\text { final } \\
\text { patamar } \\
30 \mathrm{~min} \\
\end{array}$ \\
\hline 100 & 0 & 6 & $20^{\circ} \mathrm{C}$ & $450^{\circ} \mathrm{C}$ & $650^{\circ} \mathrm{C}$ & $900{ }^{\circ} \mathrm{C}$ \\
\hline 95 & 5 & 6 & $20^{\circ} \mathrm{C}$ & $450^{\circ} \mathrm{C}$ & $650^{\circ} \mathrm{C}$ & $900^{\circ} \mathrm{C}$ \\
\hline 93 & 7 & 6 & $20^{\circ} \mathrm{C}$ & $450^{\circ} \mathrm{C}$ & $650^{\circ} \mathrm{C}$ & $900{ }^{\circ} \mathrm{C}$ \\
\hline 90 & 10 & 6 & $20^{\circ} \mathrm{C}$ & $450^{\circ} \mathrm{C}$ & $650^{\circ} \mathrm{C}$ & $900{ }^{\circ} \mathrm{C}$ \\
\hline
\end{tabular}

Fonte: Autores, (2018).

Após queima os corpos de prova foram medidos através de paquímetro digital, da marca ZAAS Precision, modelo Stainless Hafoi, afim de analisar comparativamente com as 
medições dos corpos de prova verde e seco. Foi medido comprimento, largura e espessura respectivamente afim de verificar o valor da retração linear.

\section{II.3 ENSAIOS FÍSICOS E MECÂNICOS}

Foram realizados os seguintes ensaios nos corpos de prova:

\footnotetext{
Determinação da unidade de prensagem

-Perda ao Fogo (PF)

- Retração Linear após a queima (RL)

- Absorção de Água (AA)

- Porosidade Aparente (PA)

- Massa Especifica Aparente (MEA)

- Tensão a Ruptura à Flexão (TRF)

- Difração de Raio-X (DRX)
}

Estes ensaios físicos e mecânicos são de extrema importância, onde através desses ensaios que se determina a qualidade do produto final. Para todos os ensaios listados a cima, foi realizado de acordo com os parâmetros estabelecidos pelas NBRs $15.270-1,15.270-2$ e 15.270-3.

\section{II.3.1 UMIDADE DE PRENSAGEM}

A umidade de prensagem foi obtida através dos valores medidos da massa úmida $(\mathrm{Mu})$ e massa seca $(\mathrm{Ms})$, as quais foram realizados antes e após secagem, respectivamente. $\mathrm{O}$ valor de umidade de prensagem foi calculado utilizando a seguinte equação:

$$
U(\%)=\frac{(M u-M s)}{M s} \times 100(g)
$$

Onde:

$\mathrm{U}=$ Umidade

Um = Massa úmida

Ms = Massa seca

\section{II.3.2 PERDA AO FOGO}

Para calcular o valor do percentual da variação de massa após queima a $900^{\circ} \mathrm{C}$, utilizou-se a equação de perda ao fogo:

$$
P F(\%)=\frac{(M u-M q)}{M s} \times 100(g)
$$

$\mathrm{PF}=$ Perda ao fogo

Ms = Massa seca

$\mathrm{Mq}=$ Massa após queima

\section{II.3.3 RETRAÇÃO LINEAR}

Os corpos de prova foram medidos seus comprimentos antes da secagem (L0) e após a queima (L1), determinando a retração linear dos corpos de prova após a queima, por meio da seguinte equação:

$$
R L(\%)=\frac{(L 0-L 1)}{L 0} \times 100(\mathrm{~mm})
$$

Onde:

L0 $=$ Comprimento verde

L1 = Comprimento após queima

\section{II.3.4 ABSORÇÃO DE ÁGUA (AA)}

Para a realização desses ensaios, as amostras foram submetidas a dois procedimentos estabelecidos pela NBR 15.2703 , necessários para calcular a absorção de água. São eles: medidas de massa imersa e massa úmida, onde após determinação da massa seca as amostras foram submetidas à água fervente. Neste processo os corpos de prova foram colocados em um recipiente de dimensões apropriadas, preenchido com água à temperatura ambiente, em volume suficiente para mantê-los totalmente imerso (Figura 15).

A água foi gradativamente aquecida até o ponto de ebulição, onde os corpos-de-prova foram mantidos completamente imersos por duas horas. Transcorrido o tempo de imersão de duas horas de fervura, foi interrompida a operação e os corpos de prova foram resfriados via substituição lenta da água quente do recipiente por água à temperatura ambiente.

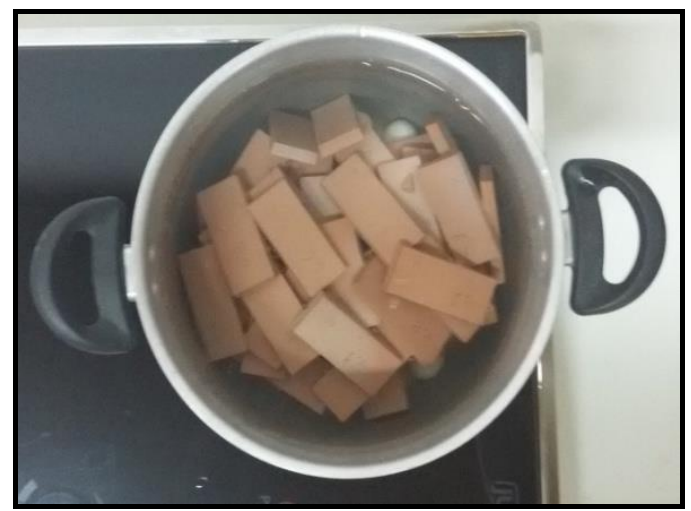

Figura 15: Recipiente para aquecimento dos corpos de prova. Fonte: Autores, (2018)

Com a água do recipiente à temperatura ambiente, os corpos de prova saturados foram removidos e colocados em bancada para permitir o escorrimento do excesso de água. A água remanescente foi removida com o auxílio de um pano limpo e úmido, observando-se que o tempo decorrido entre a remoção do excesso de água na superfície e o término das pesagens não foi inferior a $15 \mathrm{~min}$, como estabelece a norma.

Todas as medidas de massa foram realizadas, em balança analítica da marca Adventurer OHUS, modelo ERC Classe II, calibrada de acordo com a portaria [11].

\section{II.3.5 MEDIDA DA MASSA IMERSA DO CORPO DE PROVA (MI)}

Cada corpo de prova teve sua massa medida quando imerso em água (Pi). O tempo que a água ficou em ebulição foi o suficiente para que a água penetrasse nos poros abertos formados pela queima dos corpos de prova. Os valores dessa medida são utilizados para o cálculo da porosidade aparente e da massa especifica aparente.

\section{II.3.6 MEDIDA DA MASSA ÚMIDA DO CORPO DE PROVA (MU)}

Após a medida da massa imersa $(\mathrm{Pi})$, foram retirados os corpos de prova da água, em seguida enxugados em papel absorvente e, novamente foi medido a massa úmida dos corpos de prova fora da água $(\mathrm{Pu})$. Os dados dessa medida, além de mostrar a variação da massa devido à absorção de água pelos poros abertos formados durante a queima dos corpos de prova, também 
é importante para os cálculos da porosidade aparente e massa específica aparente. Para o cálculo de absorção de água das amostras, foi utilizada a seguinte equação:

$$
A A(\%)=\frac{(P u-P s)}{P s} \times 100(g)
$$

Onde,

$\mathrm{Pu}=$ massa do corpo úmido $(\mathrm{g})$

Ps $=$ massa corpo seco $(\mathrm{g})$

\section{II.3.7 POROSIDADE APARENTE (PA)}

A porosidade das amostras foi determinada através da seguinte equação:

$$
P A(\%)=\frac{(P u-P s)}{P s} \times 100(g)
$$

$\mathrm{Pi}=$ massa do corpo imerso em água $(\mathrm{g})$

\section{II.3.8 MASSA ESPECÍFICA APARENTE (MEA)}

A massa especifica aparente é a medida da densidade dos corpos de prova, a qual foi calculada utilizando a seguinte equação:

$$
\operatorname{MEA}(\%)=\frac{P s}{P u-P i} \times 100(g)
$$

\section{II.3.9 TENSÃO A RUPTURA À FLEXÃO (TRF)}

A medida de tensão e ruptura à flexão foi determinada através do fleximetro, marca NANNETTI FAENZA, modelo CC 6696. 20076, equipamento mostrado na (Figura 16).

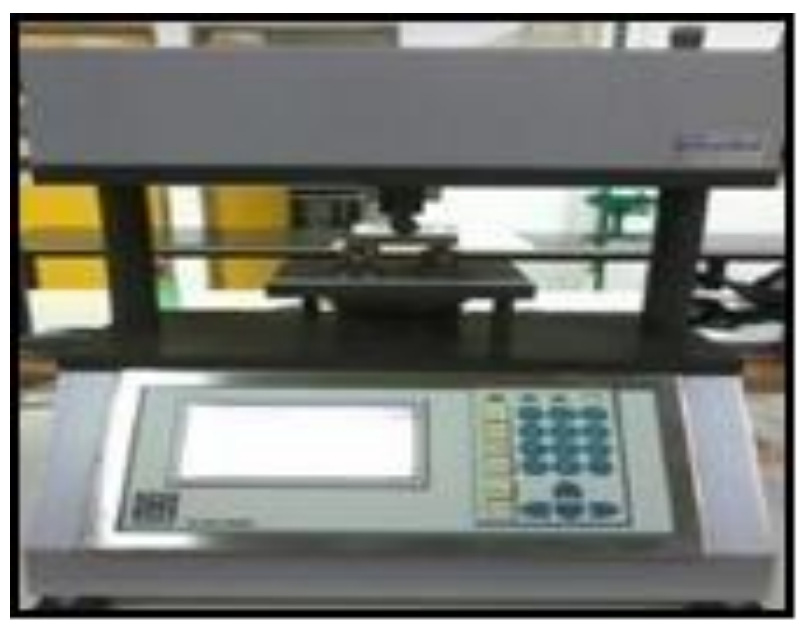

Figura 16: Flexímetro para Teste de tensão de ruptura e flexão nos corpos de provas.

Fonte: Autores, (2018).

Os corpos foram alinhados sobre os mancais fixado na base do equipamento, com distância entre as peças da ordem de $20 \%$ vinte por cento em relação ao comprimento do corpo de prova. $\mathrm{O}$ aparelho foi calibrado utilizando-se as programações de número 13, existente no equipamento onde foi obtido os resultados em unidades de $\mathrm{Kgf} / \mathrm{mm}^{2}$.

\section{RESULTADO E DISCUSSÃO III.1 GRANULOMETRIA}

As distribuições granulométricas das amostras estudadas (Figura 17), apresentam uma granulometria fina, com valores a $90 \%$ do material passando na peneira de $0,075 \mathrm{~mm}$. Segundo [12], a argila com a granulometria fina possui um alto índice de plasticidade, favorecendo quando utilizado para fins de produtos cerâmicos, conferindo maior resistência de contração e mecânica. [13] ao se analisar 5 tipos de $\operatorname{argila}(\mathrm{A}, \mathrm{B}, \mathrm{C}, \mathrm{D}$ e E) identificou que as argilas com a granulometria mais parecida foi a $\mathrm{A}$ e a $\mathrm{E}$, logo ao observar a plasticidade das amostras identificou que a maior diferença em porcentagem estava entre a amostra A e amostra E, chegando a conclusão que essa variação de plasticidade deve está associada a diferença minerológica ou no teor de matéria orgânica.

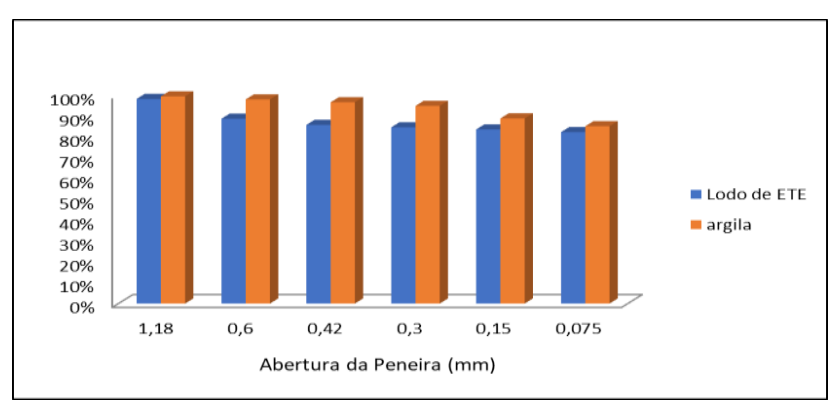

Figura 17: Distribuição Granulométrica das amostras de lodo e da argila.

Fonte: Autores, (2018).

\section{III.1.1 FLUORESCÊNCIA DE RAIO-X}

Nos resultados das análises de fluorescência de raio-X em amostra de argila e do lodo de ETE, ambos secos a $110^{\circ} \mathrm{C}$ em estufa por 24 horas. Observa-se na figura 18, que os elementos encontrados tanto na argila como no lodo, são Óxido de Alumínio (A12O3) e Óxido de Silício (SiO2).

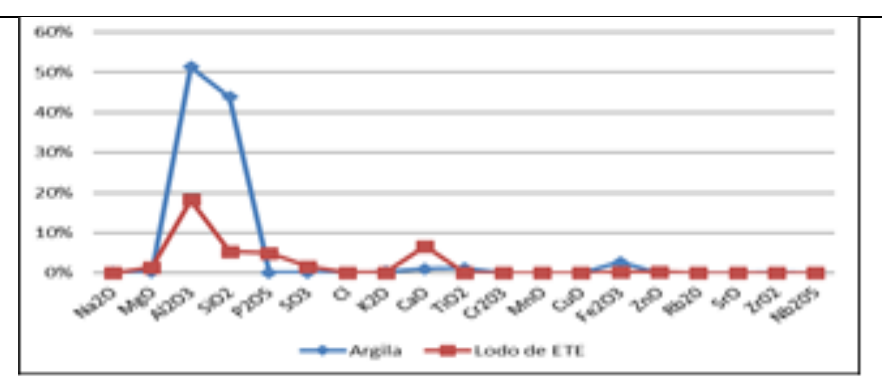

Figura 18: Fluorescência de raio-X em argila e no lodo. Fonte: Autores, (2018).

Mesmo obtendo maior concentração nas duas amostras (Lodo e Argila) o Óxido de Alumínio (A12O3) demonstrou uma variação de aproximadamente $35 \%$ entre os materiais de $0 \%$ e $10 \%$ de peso do lodo. Segundo [14] a concentração dos óxidos quantificados (Al2O3 e SiO2) é característico em argila para a fabricação de cerâmica vermelha. Logo o resultado dos elementos químicos obtido na amostra do lodo de ETE (em estudo) é compatível para incorporação na argila para fabricação de cerâmica vermelha. A semelhança entre os materiais é importante para evitar reações indesejadas durante o processo de queima dos corpos de prova. 


\section{III.1.2 DIFRAÇÃO DE RAIO -X}

No difratograma obtido da argila analisada por difração de raio-X (RDX), foi constatado que a argila coletada das proximidades da rodovia Manoel Urbano no município de Iranduba é constituída de duas fases mais acentuadas: caulinita $(\mathrm{A} 12 \mathrm{Si} 2 \mathrm{O} 5(\mathrm{OH}) 4)$, quartzo $(\mathrm{SiO} 2)$. Ao considerar os resultados das análises químicas da argila através do difratograma (Figura 19), pode-se observar que a presença de Quartzo é bastante intensa. Os demais elementos presentes não terão influência no processo de fabricação de tijolos, por estarem em baixas concentrações. Segundo [15] os resultados obtidos são caracteristicos da região, pois na análise das nove amostras coletadas foram encontradas presença marjoritária de Quartzo e Caulinita.

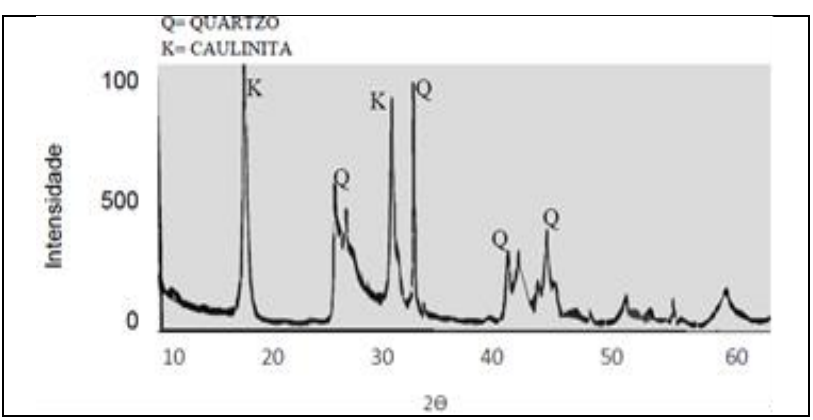

Figura 19. Difratograma de raio-X na argila. Autores (2018). Fonte: Autores, (2018).

A Figura 20 mostra o difratograma do resíduo, onde se percebe maiores picos os quais, assim como na argila, mostram a presença de Quartzo e Caulinita com maior intensidade, sendo a Caulinita a majoritária. Segundo [16], a Caulinita tem maior intensidade no Lodo devido a adição de cal em uma das fases de tratamento (físico-químico) do efluente.

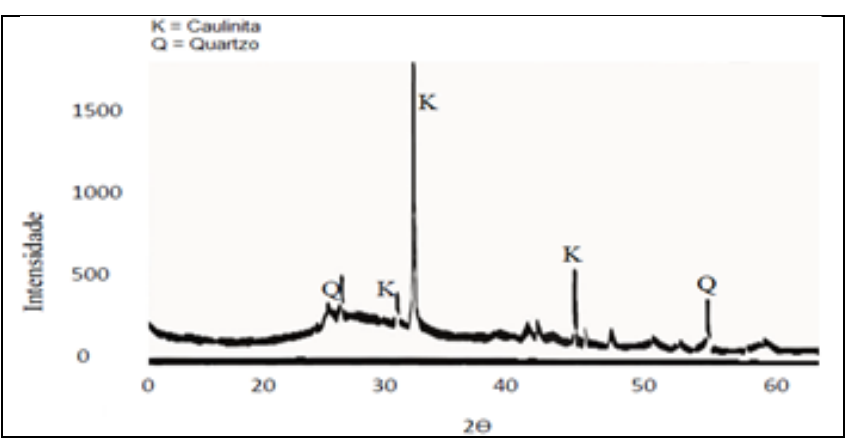

Figura 20: Difratograma de raio-X no resíduo de ETE. Fonte: Autores, (2018).

\section{III.2 ANÁLISES FÍSICAS E MECÂNICAS NOS CORPOS DE PROVA APÓS QUEIMA A $900^{\circ} \mathrm{C}$.}

Os ensaios realizados foram de retração linear (RL), absorção de agua (AA), porosidade aparente (PA), massa especifica aparente (MEA) tensão de ruptura (TRF), após a queima em temperatura de $900^{\circ} \mathrm{C}$, com percentual de quatro amostras de resíduo nas concentrações de $0 \%, 5 \%, 7 \%$ e $10 \%$, onde foi utilizado 5 corpos de prova para cada ensaio, com resultados descritos na (Tabela 5).

Tabela 5: Resultados dos ensaios físicos e mecânicos da homogeneização da argila com o lodo.

\begin{tabular}{|r|r|r|r|r|r|}
\hline \multirow{2}{*}{$\begin{array}{c}\text { Nomenclatura } \\
\text { / Formulação }\end{array}$} & \multicolumn{5}{|c|}{ Temperatura de Queima - 900ㄷ } \\
\cline { 2 - 6 } & RLq (\%) & AA(\%) & Pa (\%) & MEA (\%) & TRF (Kgf/mm²) \\
\hline $0 \%$ & 3,31 & 11,21 & 21 & 1,87 & 2,42 \\
\hline $5 \%$ & 3,48 & 8,28 & 16,34 & 1,97 & 3,02 \\
\hline $7 \%$ & 3,15 & 10,64 & 20,09 & 1,89 & 2,27 \\
\hline $10 \%$ & 3,71 & 9,82 & 18,88 & 1,92 & 2,35 \\
\hline
\end{tabular}

Fonte: Autores, (2018).

\section{III.2.1 RETRAÇÃO LINEAR (RL)}

A partir da Tabela 5, pode-se observar a representação gráfica da retração linear (RL) após queima em função da formulação de $0 \%, 5 \%, 7 \%$ e $10 \%$ de resíduo adicionado a massa cerâmica, com temperatura de sinterização de $900^{\circ} \mathrm{C}$ (Figura 21).

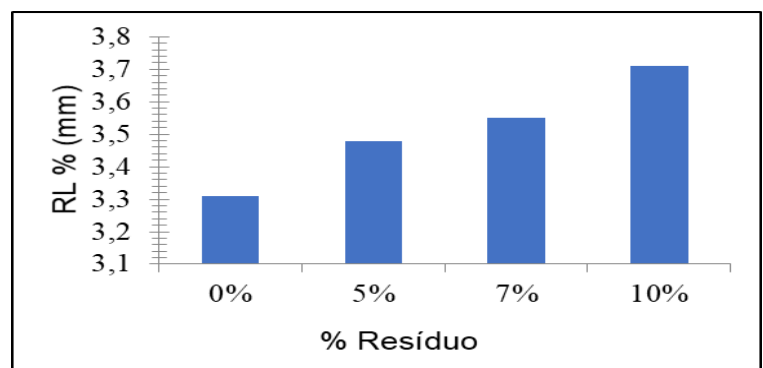

Figura 21: Retração linear nos corpos de prova (RL). Fonte: Autores, (2018)

Nota-se que houve aumento gradativo chegando a uma diferença máxima de $0,4 \%$ na retração linear entre $0 \%$ em peso de lodo na massa cerâmica, a incorporação de $10 \%$ em peso de lodo na massa cerâmica, segundo [17] esse comportamento indica um favorecimento no processo de sinterização dos corpos de prova. O aumento de $15 \%$ de peso do lodo não altera significativamente a retração linear dos corpos de prova e sim o aumento da temperatura [18].

De acordo com [19] todos valores retração apresentados estão dentro dos limites para esta propriedade (abaixo de 8\%).

\section{III.2.2 ABSORÇÃO DE ÁGUA (AA)}

De acordo com [20] recomenda-se que tijolos furados possuam valores de absorção de água entre 8 a $22 \%$, logo os corpos de prova estão dentro do limite permitido, em função do percentual de resíduo incorporado à argila, nota-se que a medida que se aumenta a quantidade de resíduo, se tem um decréscimo na absorção de água. Observa-se que absorção entre $0 \%$ e $10 \%$, está entre 9 a $11 \%$, valores aproximados (Figura 22).

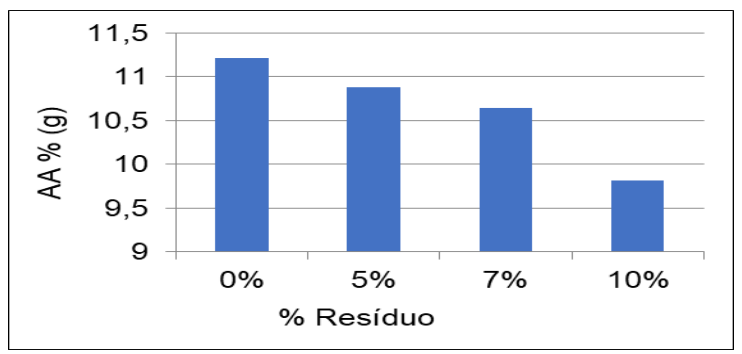

Figura 22: Absorção de água dos corpos de prova (AA). Fonte: Autores, (2018).

Segundo [21] a absorção de água é crescente proporcionalmente com a adição de lodo na massa cerâmica, 
justifica-se pelo fato de o lodo conter bastante matéria orgânica chegando a volatizar bem mais rápido devido o desprendimento de gases.

\section{III.2.3 POROSIDADE APARENTE (PA)}

A Figura 23 representa os resultados das médias de porosidade aparente em função das formulações com percentual de resíduo incorporado na massa cerâmica de $0 \%, 5 \%, 7 \%$ e $10 \%$, com temperatura de sinterização de $900^{\circ} \mathrm{C}$.

Segundo [22] os valores recomendados para porosidade aparente é de 17 a $35 \%$ na fabricação de tijolos furados.

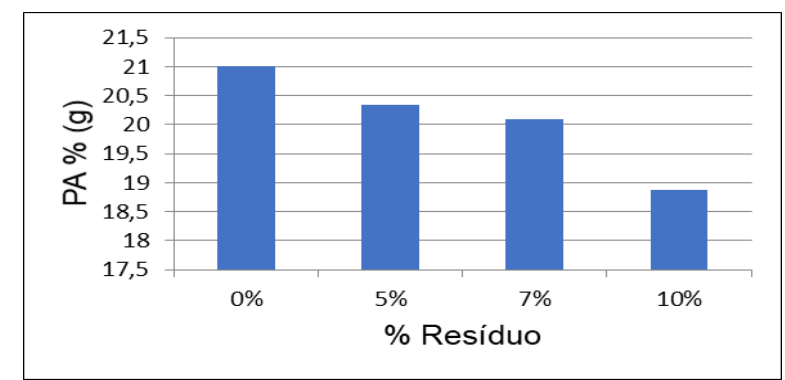

Figura 23: Porosidade aparentedos corpos de prova (PA). Fonte: Autores, (2018).

Observasse que há um decréscimo de porosidade em função do percentual de resíduo incorporado na formulação da massa cerâmica. De acordo com [23] este comportamento está de acordo com o aumento da temperatura, uma vez que há a diminuição de absorção é semelhante ao decrescimento de porosidade. Não existe discrepância entre os percentuais de $0 \%$, $5 \%, 7 \%$ e $10 \%$, estando os valores de decréscimo entre $18 \%$ e $21 \%$, resultado de ensaio realizado nos corpos de prova após queima em $900^{\circ} \mathrm{C}$.

\section{III.2.4 MASSA ESPECÍFICA APARENTE (MEA)}

A massa específica aparente é analisada em função da formulação de massa cerâmica considerando os percentuais de resíduo adicionado à massa argilosa de 0\%, 5\%, 7\% e 10\%, queimado a uma temperatura de $900^{\circ} \mathrm{C}$.

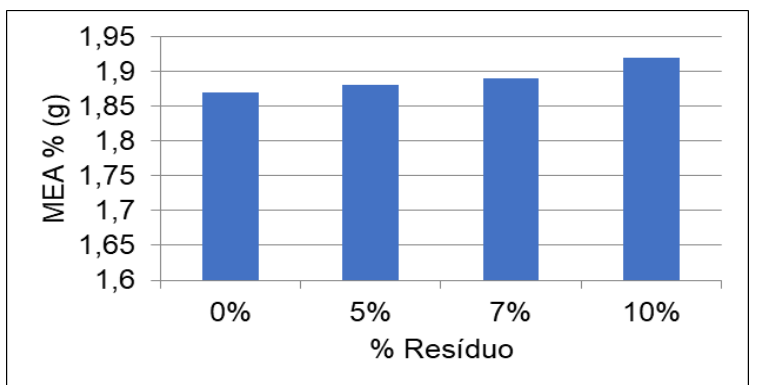

Figura 24: Massa especifica aparente (MEA) dos corpos de prova na temperatura a $900^{\circ} \mathrm{C}$.

Fonte: Autores, (2018).

Segundo [22] os tijolos furados devem possuir valores de massa específica aparente de no mínimo $1.7 \mathrm{~g} / \mathrm{cm}^{3}$.

Na Figura 24 nota-se que há uma diferença mínima de porcentagem, a medida de massa específica aparente tem um pequeno acréscimo em função do aumento de percentual de lodo de ETE. Esta pequena diferença entre os valores demonstram um bom desempenho do resíduo incorporado a massa cerâmica. Estes resultados são justificados em função da densidade do resíduo incorporado, e a matéria orgânica que dissipada no momento da queima dos corpos de prova.

Segundo [24] o aumento da massa específica aparente está relacionado com o aumento da temperatura, com a absorção de água e porosidade iniciando o processo de sinterização a partir de $850{ }^{\circ} \mathrm{C}$ e a partir de $950{ }^{\circ} \mathrm{C}$ há o início da formação de fase líquida que rapidamente fecha os poros dos corpos cerâmicos.

\section{III.2.5 TENSÃO DE RUPTURA À FLEXÃO (TRF)}

O resultado de tensão de ruptura à flexão dos corpos de prova em função do percentual de resíduo incorporado à massa cerâmica que foi de $0 \%, 5 \%, 7 \%$ e $10 \%$, com temperatura de queima de dos corpos de prova de $900^{\circ} \mathrm{C}$.

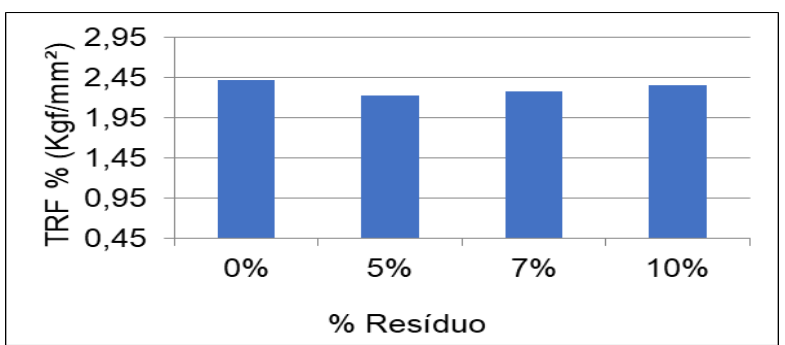

Figura 25: Tensão de Ruptura à Flexão dos corpos de prova (TRF). Fonte: Autores, (2018).

Pode-se observar que a tensão de ruptura à flexão tem uma pequena diminuição em relação ao aumento do percentual de resíduo incorporado à massa cerâmica, variando nos resultados.

Estes valores de tensão a ruptura, não influência de forma negativa nos corpos de prova, uma vez que a escala entre o valor, considerando os percentuais de resíduo entre $0 \%$ e $10 \%$, é extremamente insignificante para a determinação da qualidade do produto final. A tensão de ruptura a flexão tende aumentar com o aumento da temperatura [17].

Esta observação não é possível para este estudo, uma vez que foi utilizado apenas uma temperatura de $900^{\circ} \mathrm{C}$. Para este caso resultado de tensão de ruptura está de acordo com os parâmetros da NRB - 15270 .

\section{III.2.6 DIFRAÇÃO DE RAIO-X NOS CORPOS DE PROVA APÓS QUEIMA}

Nota-se que com esse percentual após queima, houve um favorecimento para o aumento dos picos de quartzo, e uma redução na intensidade nos picos de caulinita (Figura 26). A redução da caulinita, ocorre após sinterização dos corpos de prova para que aconteça uma organização linear dos minerais presentes, possibilitando uma qualidade satisfatória do produto final.

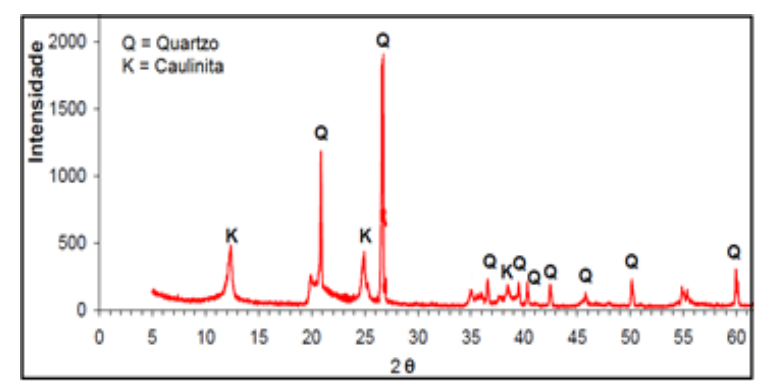

Figura 26: Difratograma de Raio -X nos corpos de prova após queima $\left(900^{\circ} \mathrm{C}\right)$ contendo $10 \%$ de lodo de ETE incorporado à argila.

Fonte: Autores, (2018). 
Segundo [18], isso ocorrem devido a adição de resíduo (lodo), pois com o aumento da temperatura a materia orgânica se decompoe e ocorre a desidroxilação da caulinita para metacaulinita amorfa, dando lugar a para o quartzo, mineral com maior resistência ao processo de sinterização.

\section{CONCLUSÃO}

Apesar das amostras serem de fontes totalmente distintas ao caracterizar a argila e o resíduo de ETE, constatou-se que há uma semelhança entre os elementos químicos componentes. Nas análises a partir de fluorescência foi possível observar um elevado percentual de Óxido de Alumínio (Al2O3), sílica (SiO2), e baixo teor de oxido de ferro ( $\mathrm{Fe} 2 \mathrm{O} 3)$. Na difração de raio-X, foi identificado na argila e no resíduo elevada presença de quartzo (SiO2), Caulinita (Al2Si2O5(OH)4). Esta semelhança dos argilominerais nas matérias-primas se justifica por ambos serem proveniente de sedimentos geológico da região amazônica. De acordo com as características da argila e resíduo, facilita sua mistura para fabricação de tijolos. A viabilidade da incorporação do resíduo na argila se confirma por meio das análises físicas e mecânicas, que através destas ver-se resultados satisfatórios para retração linear, absorção de água, porosidade aparente, massa específica aparente e tensão de ruptura a flexão, ou seja, todos resultados foram de acordo com os parâmetros estabelecidos pela [25]. Por meio deste estudo é possível determinar que a agregação de até $10 \%$ em peso de lodo da ETE na massa cerâmica não interferi na qualidade do produto final, minimizando os impactos ambientais gerados na disposição final deste resíduo.

\section{AGRADECIMENTOS}

Muito obrigada aos professores: M.Sc. Ítalo Jorge Tavares Jimenez, Sebastião Batista Ramos Junior, por abrir as portas mostrando-me o caminho e dando apoio durante as análises físicas e mecânicas, M.Sc. Káren Lorena Lobo Prado, pelo seu comprometimento, incentivo, Dra. Cláudia Cândida Silva, pela oportunidade e orientação para realização das análises de fluorescência de Raio-X no laboratório de química do Grupo Crowfoot da Escola Superior de Tecnologia da Universidade do Estado do Amazonas - UEA, ao Dr. Raimundo Humberto Cavalcante Lima do laboratório do departamento de geociências da Universidade Federal do Amazonas UFAM, pela atenção e apoio para realização das análises de difração de Raio $-\mathrm{X}$, ao Dr. Carlos Cleomir de Souza Pinheiro do lab. Temático Institucional de Química de Produtos Naturais (LTQPN) do Instituto de Pesquisa Nacional da Amazônia (INPA) pela liberação para a realização da queima dos corpos de prova. Ao técnico Darlei dos A. Lavor do laboratório de Geotecnia (mecânica dos solos) da Universidade Uninorte pelo auxilio nas análises granulométricas. Sem vocês seria impossível o desenvolvimento dos resultados das análises. Em especial agradeço as empresas que cederam as matérias primas (lodo e argila) para a realização da pesquisa.

\section{REFERÊNCIAS}

[1] Novais, V.M.S; Desafio para uma efetiva gestão ambiental no Brasil, Bahia, 2011.
[2] Bonati, J; Diagnóstico e análise de impactos ambientais no município de cruzeiro do sul e região, vale do juruá, estado do acre, amazônia ocidental, 2011.

[3] Mazzer, C; Introdução à gestão ambiental de resíduos, 2004.

[4] Hinz, R.T.P et al; Sustentabilidade ambiental das organizações através da produção mais limpa ou pela Avaliação do Ciclo de Vida. Santa Catarina, 2006.

[5] Nova, O; Disponível em:

<http://www.opersan.com.br/solucoes/tratamento-de-efluentes/>. Acesso em 12 de setembro de 2018.

[6] Imhoff, Karl e Klaus; Manual de Tratamento de Águas Residuárias. Trad. DeM.L. Hess. São Paulo: Ed. Edgard Blücher,1996.

[7] Bettiol, W; Camargo, O.A. de (Coord.); Lodo de Esgoto: Impactos Ambientais na Agricultura. Jaguariúna: Embrapa Meio Ambiente, 2006. P317.

[8] Araujo, N.C. et al; Propriedades mecânicas de tijolos fabricados com solo e água residuária de mandioca. Revista Verde (Pombal - PB - Brasil) v. 10, n.2, p. 213 - 217, abr-jun, 2015.

[9] Cabral, E.M et al;Utilização de massas cerâmicas na produção de agregado sintético de argila calcinada para uso em concreto, 2008.

[10] Fernandes, et al; Reciclagem do Lodo da Estação de Tratamento de Efluentes de uma Indústria de Revestimentos Cerâmicos. Parte 1: Ensaios Laboratoriais, 2003.

[11] INMETRO. Instituto Nacional de Metrologia, Normalização e Qualidade Industrial, Dimel $n^{\circ}$ 0021/2004, de 28 de janeiro de 2010.

[12] Prado, C.M.O; Caracterização química e mineralógica das argilas utilizadas na produção de cerâmica vermelha no estado de Sergipe, 2011.

[13] Macedo, R.S, et al; Estudo de argilas usadas em cerâmica vermelha, p.411,Campinas Grande, 2008.

[14] Araujo, F.S.D; Influencia do lodo de ETE na massa para fabricação de cerâmica vermelha. 2008. Dissertação (Mestrado ciência e engenharia de materiais) - Universidade Rio Grande do Norte, Natal, 2008.

[15] Santana, G.P; et al; Propriedades físicas, químicas e mineralógicas de solos contaminados do pólo industrial de manaus, Scientia Amazonia, v. 3, n.1, 58-64, 2014 Revista on-line http://www.scientia.ufam.edu.br Jan-Abr ISSN:2238.1910, 2013.

[16] Zanoni, S.M; Reutilização de resíduos de indústria têxtil como matéria-prima em cerâmica vermelha, 2013

[17] Jimenez, I.J.T; Utilização do Lodo de Estação de Tratamento de Efluentes da Industria de Injeção Plástica como Matéria-Prima para Industria Cerâmica, 2009. Dissertação (Mestrado em Engenharia Elétrica) - Programa de Pós-Graduação em Engenharia Elétrica. Universidade Federal do Pará, Centro de Tecnologia - ITEC. Pará, 2011. 
[18] Oliveira, E.M.S; Holanda, J.N.F; Influência da adição de resíduo (lodo) de estação de tratamento de águas nas propriedades e microestrutura de cerâmica vermelha, 2008.

[19] ABNT - Associação Brasileira de Normas Tecnicas. NBR 15.270 - 2. Resistência Característica à Compressão Estimada, determinada de Acordo com 5.3, 2005.

[20] ABNT - Associação Brasileira de Normas Tecnicas, NBR 15.270-1 31- ago-05 Componentes cerâmicos - Parte 1: Blocos cerâmicos para alvenaria de vedação - Terminologia e requisitos, 2005.

[21] herek, 1.c.s, et al;Incorporação de lodo de lavanderia industrial na fabricação de tijolos cerâmicos, 2009.

[22] Amorim, F.R; Co-processamento de dregs em argila para produção de cerâmica vermelha. 2007. Dissertação (Mestrado em Saneamento) - Universidade Federal de Minas Gerais, Belo Horizonte, MG, 2007

[23] Collatto, D. et al;Influência da granulometria do resíduo da celulose nas propriedades do material cerâmico, vol.4, 2008.

[24] Vieira, G; Da Silva, D.F; Estudo da adição de lodo gerado pela indústria metal mecânica na fabricação de tijolos de cerâmica vermelha. E-Tech: Tecnologias para Competitividade Industrial, Florianópolis, n. esp. Metalmecânica, p. 69-91, 2012.

[25] ABNT - Associação Brasileira de Normas Tecnicas, NBR 15.270-3. Componentes cerâmicos Parte 3: Blocos cerâmicos para alvenaria estrutural e de vedação - Métodos de ensaio, 2005. 